\title{
Lugano Lymphoma Response Classification
}

National Cancer Institute

\section{Source}

National Cancer Institute. Lugano Lymphoma Response Classification. NCI Thesaurus.

Code C142790.

A lymphoma response criteria system developed at the 11th International Conference on Malignant Lymphoma (ICML) in Lugano, Switzerland, June 2011. 